\title{
La contribución de la tecnología digital al desarrollo y transformación de la ilustración contemporánea
}

Marta Riera Táboas martarierataboas@hotmail.com Universidad de Vigo. Grupo Investigación DX7, España

Reference

Pinto, Ana Lúcia; Zagalo, Nelson; Coquet, Eduarda; (2012) "From a click to a gesture: a contribution to defining the concept of children's e-picturebooks", p. 223-228 . In: Barbosa, Helena; Quental, Joana [Eds]. Proceedings of the 2nd International Conference of Art, Illustration and Visual Culture in Infant and Primary Education. São Paulo: Blucher, 2015. ISSN 2318-695X, ISBN: 978-989-98185-0-7 DOI 10.5151/edupro-aivcipe-43

Resumen

La tecnología digital ha supuesto para el ilustrador contemporáneo una auténtica revolución en su práctica profesional, tanto en el proceso del trabajo como en términos de visibilidad y de relación con sus clientes. La comunicación instantanea que la red ofrece posibilita la realización y entrega de un encargo desde cualquier punto del planeta, favoreciendo la inmediatez del proceso y la independencia del ilustrador respecto de otros intermediarios. Impulsada por la herramienta digital, la ilustración contemporánea vive un proceso de enriquecimiento que le permite abarcar ámbitos menos transitados que van desde la aplicación textil, complementos de moda o murales en espacios comerciales.

Palabras clave Ilustración, tecnología, Internet, soportes, profesión

Abstract

Digital technology has meant for nowadays illustrators a real revolution in their careers, both in the work development as in terms of visibility and the way of dealing with costumers. Instant communication due to the web, allows them to perform and deliver from their own studio the work ordered from everywhere around the world, increasing the quickness of the process and the independence of the illustrator from other agents. Inspired by digital tools, contemporary illustration goes through a revival that allows to cover fields traditionaly less worked, from textiles, fashion accesories or murals at commercial spaces.

\section{Introducción.}

La historia de la ilustración está vinculada al desarrollo de las técnicas gráficas y a la influencia de los movimientos artísticos de cada momento. Si bien en un principio todas las manifestaciones artísticas constituyen piezas únicas, con la aparición del papel y de las técnicas de grabado, se introduce el concepto de multiplicidad que tendrá su punto álgido con la prensa de Gutemberg de 1554 .

El segundo gran hito en el desarrollo de las técnicas de reproducción lo constituye el descubrimiento de la litografía, medio que explotarán los artistas atraídos por la inmediatez y libertad de trazo que permite la técnica al dibujar directamente sobre la piedra litográfica con el lápiz graso. Este momento marca el nacimiento del cartel publicitario, que ofrecerá hasta el presente un campo de creatividad enorme para ilustradores y diseñadores gráficos y que establecerá un vínculo ya inquebrantable entre ilustración, diseño y moda.

La litografía evoluciona hacia otro proceso revolucionario como es la litografía offset, permitiendo una reproducción velocísima y en gran formato además de a todo color con la utilización de la fotografía y de los procesos químicos para trasladar la imagen a las planchas metálicas. 
and International Conference

Art, Illustration and Visual Culture

in Infant and Primary Education $2^{\circ}$ Congreso Internaciona

Arte, llustración y Cultura Visual en Educación Infantil y Primaria
Congresso Internacional

de Arte, Ilustração e Cultura Visual

na Educação Infantil e Primária

\section{La revolución digital.}

Figuras 1 y 2. A la izquierda: Iván Solbes, Sales (2004). Digital (FreeHand/ Photoshop). A la derecha: Gabrie Moreno. llustración publicitaria para Ron Santa Teresa (2007). Mixta (lápiz, rotulador Pilot, Photoshop).
La aparición de los ordenadores personales en los 80 revoluciona el proceso de edición y más adelante los programas específicos de dibujo como Illustrator o FreeHand; y de tratamiento de imágenes con PhotoShop, amplían los horizontes del diseño gráfico y de la ilustración de un modo ilimitado. La aportación del escaner al mundo de la ilustración es fundamental. La simplificación e inmediatez en el paso de original a archivo digital permite trabajar con mayor flexibilidad al ilustrador, que frecuentemente se ocupará él mismo de la digitalización.

El presente estudio tiene por objeto analizar como la figura del ilustrador se ha transformado durante la era digital. Si bien hacia la década de los 80 se intuye cierta recuperación de la disciplina tras décadas de crisis como consecuencia de la imposición de la fotografía, será a partir de los años 90 y del desarrollo de Internet, cuando la ilustración experimente un renacimiento que le impulse a recuperar o descubrir múltiples áreas de trabajo.

Desde el punto de vista de la práctica profesional del ilustrador contemporáneo, los ordenadores han supuesto una revolución en distintos sentidos. Por una parte, los softwares constituyen herramientas que dejan en manos del ilustrador el control de todo el proceso en la realización de la pieza, excepto quizás la impresión si de ello se encargan terceras personas. Se trate de una ilustración tradicional o digital, el artista tiene la capacidad de concretar todo el proceso en un archivo digital que enviará al cliente. Del mismo modo que la fotografía había ampliado el horizonte del proceso artístico, esta nueva tecnología creará toda una tipología de técnicas y procesos que tendrá como consecuencia la desaparición de la obra original como la conocíamos- en todas sus manifestaciones- y la implantación del archivo digital como original múltiple.

Normalmente los ilustradores emplean procesos diferentes en función de la elección del cliente, la naturaleza del proyecto dado, su destino de aplicación, o simplemente el condicionante imponderable de los plazos de entrega.

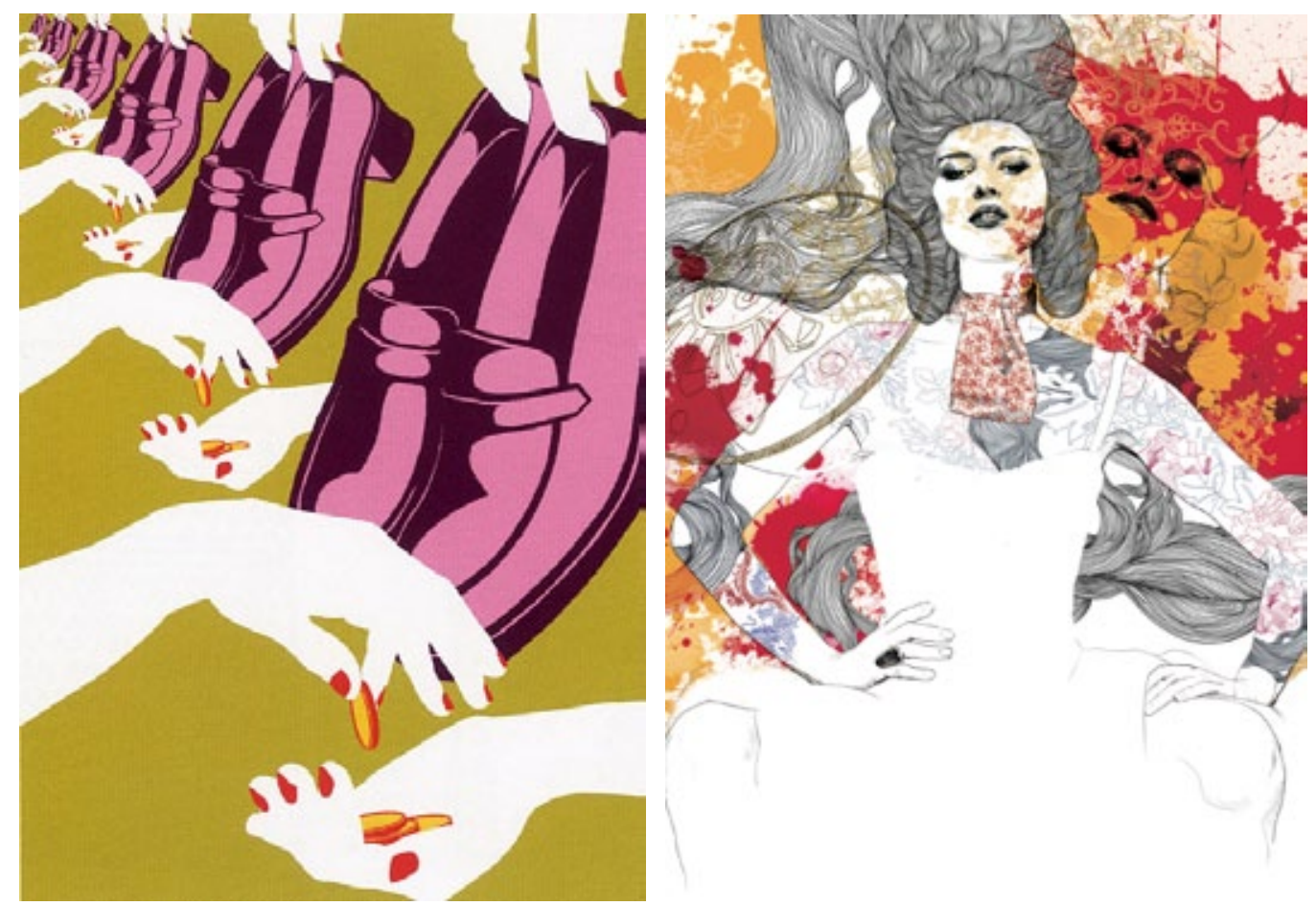

No obstante, en plena era digital infinidad de ilustradores continúan apostando por los medios y técnicas tradicionales, de base pictórica o de dibujo. Lápices, acuarelas, pasteles, tintas, óleos y acrílicos están presentes en la obra de ilustradores contemporáneos de primera línea como Berto Martínez, Arturo Elena o Montse Bernal. Este grupo de artistas encuentran en los medios más tradicionalmente relacionados con las Bellas Artes su forma de estar en la ilustración, de 
expresarse creativamente. En estos casos el original continúa siendo una pieza única que en ocasiones entrará en contacto con el mercado del arte exponiéndose en medios artísticos y vendiéndose como cualquier otra obra artística. En ocasiones estos ilustradores digitalizan el original para finalizar la obra con un software específico, pero modificando mínimamente la obra manual.

Durante los últimos años las obras realizadas con medios manuales- o que al menos simulan la impronta manual- se han revalorizado, como consecuencia de la saturación de las imágenes generadas en ordenador, e incluso debido al mal uso que se hizo con frecuencia de las herramientas digitales de dibujo y pintura. Por supuesto, también han influido las modas y tendencias tan dispares como el neo romanticismo, el graffitti o el art brut han liberado el gesto, propiciando la multiplicación de imágenes dibujadas o pintadas a mano.

Una de las aportaciones más interesantes de los programas informáticos en el campo de la ilustración es la posibilidad que ofrece para desarrollar una obra a partir de un dibujo previo realizado a mano. Según Lawrence Zeegen,

El secreto de las obras de más éxito reside en la combinación artística de lo digital y lo tradicional de un modo sutil y sin engreimiento. Usando técnicas de fotografía digital, solas o en compañía de técnicas de dibujo y pintura, y combinándolas con la práctica de la impresión en frío y en caliente, el arte callejero con plantillas y demás, este novedoso enfoque reclama nuestra atención. (Zeegen, 2007:14)

Constituye uno de los modelos de trabajo más frecuentes y en ocasiones mantiene un paralelismo con el tradicional sistema de rotulación y aplicación posterior de color o texturas. A veces estas dos funciones las realizaba el mismo ilustrador y en ocasiones un individuo dibujaba mientras que otro finalizaba el trabajo; el mismo sistema de separación de funciones nos podemos encontrar hoy en día, sobretodo en el ámbito de la animación.

El dibujo constituye la pieza única pero una vez digitalizado puede seguir diversos procesos: el dibujo se puede mantener aparentemente inalterable, sin modificar y en forma de mapa de bits- como si de una foto se tratase- para después crear áreas en las que se aplicará el color o efecto deseado. La ventaja de este sistema es que se conserva el dibujo con sus características de gesto, trazo,... conservando la apariencia manual. Pero también este dibujo original puede trazarse en el ordenador con programas como Illustrator o FreeHand. En este caso el dibujo original se transforma en vectores y no aparece en la ilustración definitiva. Este modelo de trabajo tiene la ventaja de poder adaptar la ilustración a diversos soportes y tamaños sin pérdida de calidad de imagen.

Por último, la aparición de lápices ópticos y tableros digitales ha facilitado la tarea de dibujar directamente en el ordenador, aunque son pocos los ilustradores que inician y acaban sus proyectos frente a la pantalla, con lo que el original tradicional desaparece y desde el inicio del proceso contamos con una archivo digital.

Sea cual sea el método de trabajo empleado, lo destacable es que además de una mayor independencia en el ejercicio de su profesión, los medios digitales han supuesto un abanico de posibilidades enorme para el desarrollo de la ilustración contemporánea, propiciando su regreso a distintos medios.

\section{Internet.}

Además de las nuevas posibilidades técnicas que hemos apuntado, el ilustrador cuenta con una mayor autonomía al poder concentrar todo el proceso de trabajo en su propio estudio, transformando su perfil y propiciando en muchos casos la aglutinación de la figura del ilustrador y diseñador en un único sujeto. Pero la aportación de los medios digitales se constata no sólo en el modo de trabajar o en resultado final, la aparición de Internet es la segunda revolución tras la aparición del ordenador personal, y posiblemente el descubrimiento más transcendental de nuestra historia reciente. Pero ¿qué ha supuesto Internet para el ilustrador?

1. En primer lugar, la red supone la mayor y más accesible fuente de información. En la mayoría de las ocasiones tras el encargo por parte del cliente, el ilustrador debe documentarse o buscar referencias que le permitan comenzar a elaborar bocetos. La red supone una fuente de documentación extensa y actualizada. 
end International Conference Art, Illustration and Visual Culture in Infant and Primary Education
2. Gracias a la red la comunicación entre el ilustrador y el cliente es más rápida y directa, permitiendo la resolución de un encargo en el mínimo plazo posible. Una vez el cliente contacta con el ilustrador, se inicia un intercambio de información que se inicia con el briefing, continúa normalmente con los bocetos, y se cierra con el envío del arte final. Programas específicos como You Send It posibilitan enviar por la red documentos pesados (muchas veces de modo gratuito), dejando la dependencia hacia las compañías de transporte para el pasado.

3. Internet constituye el mayor expositor posible para la obra de los creadores. Como sucede con prácticamente todo, si un ilustrador no se encuentra en Internet, no existe. Bien mediante una web individual, bien mediante un blog (cada vez más empleado por la facilidad de su gestión), los ilustradores exponen su obra-normalmente dividida en sectores de aplicación- e indican como contactarlos. También es frecuente que aporten otro tipo de datos: biografía, clientes, o si lo poseen, los datos de su agente. Las redes sociales y las cibercomunidades como Facebook, blogspot o MySpace, contribuyen también a difundir la obra de los ilustradores, quienes, como señala Alex Ceball:

(...) a diferencia del pasado, cuando fundaban sus propias revistas en las cuales publicaban sus obras y textos, ahora con certera estrategia se filtran en publicaciones de distribución planetaria para hacer lo mismo, con la diferencia que ahora su alcance es infinitamente mayor. (Ceball, 2009:6)

4. Desde el punto de vista de la captación de trabajo, resulta fundamental como la red ha facilitado el contacto entre ilustradores y agentes. Ya no es necesario que un ilustrador se lance a la búsqueda de nuevos mercados carpeta en mano, si cuenta con un profesional que lo haga en su lugar. La relación con un representante no implica el conocimiento cara a cara, pero sin embargo puede abrir para el creador opciones de trabajo en todo el mundo. La labor del agente consiste en proporcionar encargos al ilustrador, promocionarlo y ponerlo en relación con el cliente.

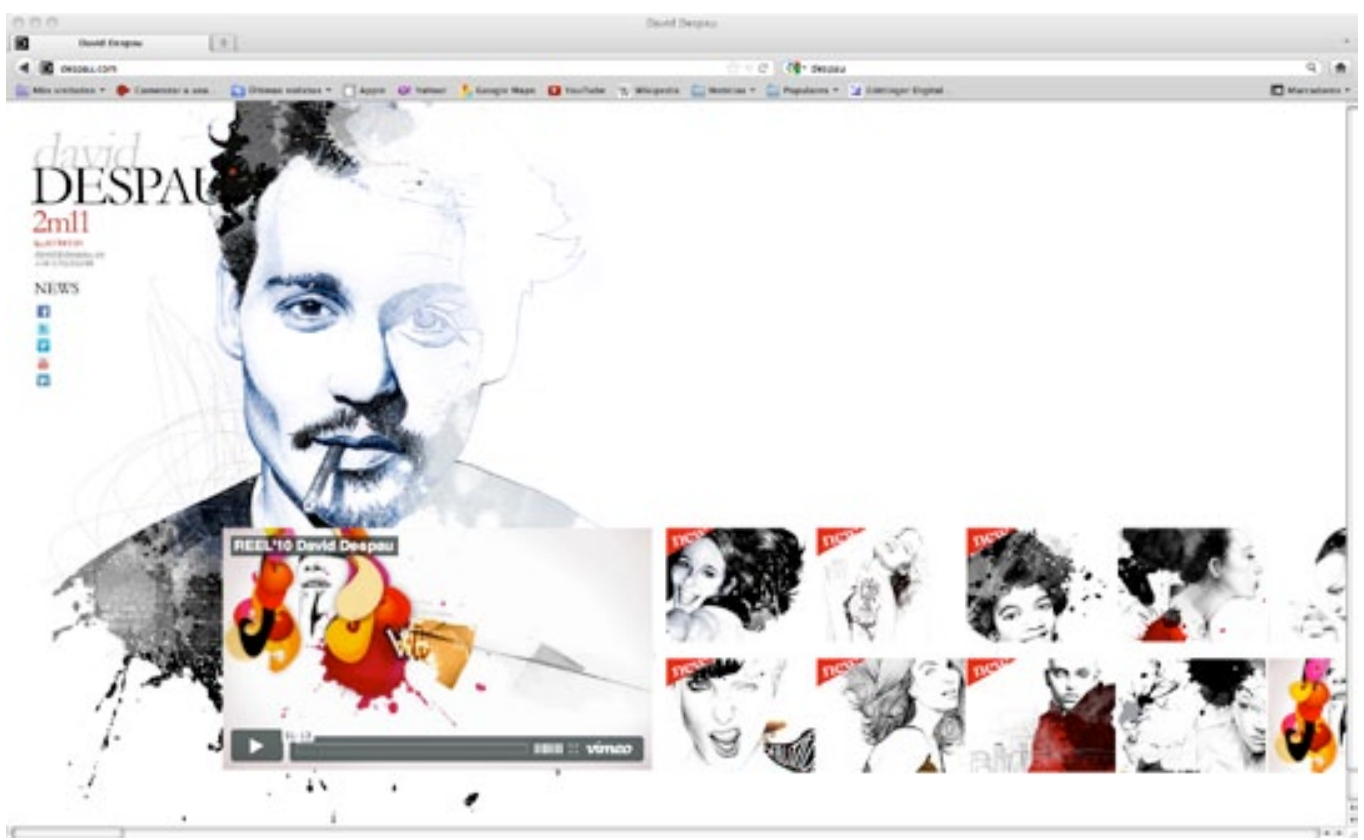

No obstante, en paises como España la figura del representante de ilustradores no acaba de consolidarse y la realidad es que aquellos ilustradores con mayor proyección trabajan con agentes internacionales. En muchos casos, los ilustradores contarán con un agente en su país de origen, y otro que le abra las puertas a mercados internacionales. Entre los representantes extranjeros con los que colaboran nuestros ilustradores se encuentran en Londres Folio (Catalina Estrada), Début Art (Gabriel Moreno), Killington Art (Miguel Gallardo, Sonia Pulido) y Eye Candy (Jaume Vilardell); en Holanda Unit (Berto Martínez, Paula Sanz); Art Department con base en Londres, Nueva York, París y Milán (Jordi Labanda), Agent ooz en París (Berto Martínez, Carmen G. Huerta, Ed Carosía, Lina Vila). 
$2^{\text {nd }}$ International Conference Art, Illustration and Visual Culture in Infant and Primary Education $2^{\circ}$ Congreso Internacional

Arte, llustración y Cultura Visual en Educación Infantil y Primaria resso Internacional

de Arte, llustração e Cultura Visual

na Educação Infantil e Primária

\title{
3. Viejos y nuevos soportes.
}

Por lo tanto, la relevancia de los ilustradores contemporáneos no sólo se fundamenta en la calidad de su obra, sino en la difusión que esta ha logrado al transcender nuestras fronteras en buena parte gracias al saber hacer de algunos de estos agentes.

Otra de las influencias más destacables de la tecnología digital, es como ha favorecido la versatilidad y adaptación de la ilustración contemporánea a diversos soportes. A pesar de que el sector editorial donde tuvo su origen sigue proporcionando encargos, viejos y nuevos ámbitos han recuperado o acogido con los brazos abiertos al ilustrador contemporáneo. Como apunta la artista gráfica Florence Manlik, sus trabajos se pueden adaptar a diversas aplicaciones, y le gusta emplear el término "plataformas" en vez de productos, a los que puede destinar sus dibujos. Como ella misma señala: "Pueden adquirir formas de modernos estampados en camisetas, vestidos, abrigos, sombreros y zapatos, pero también pueden decorar portadas de CD, fundas de discos, tapas de libros, papel para decoración (...)." (Quinn, 2009:74).

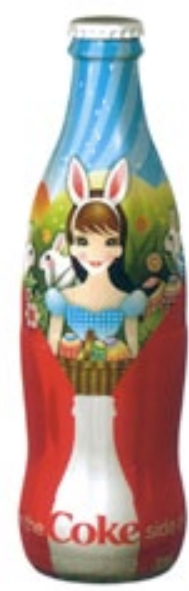

Figuras 4 y 5 . A la izquierda: Catalina Estrada, ilustraciones para Coca Cola Australia (2007). Digital. A la derecha: Lady Desidia, Rebuildssance (2012). Diseño de patterns para Texitura Magazine.
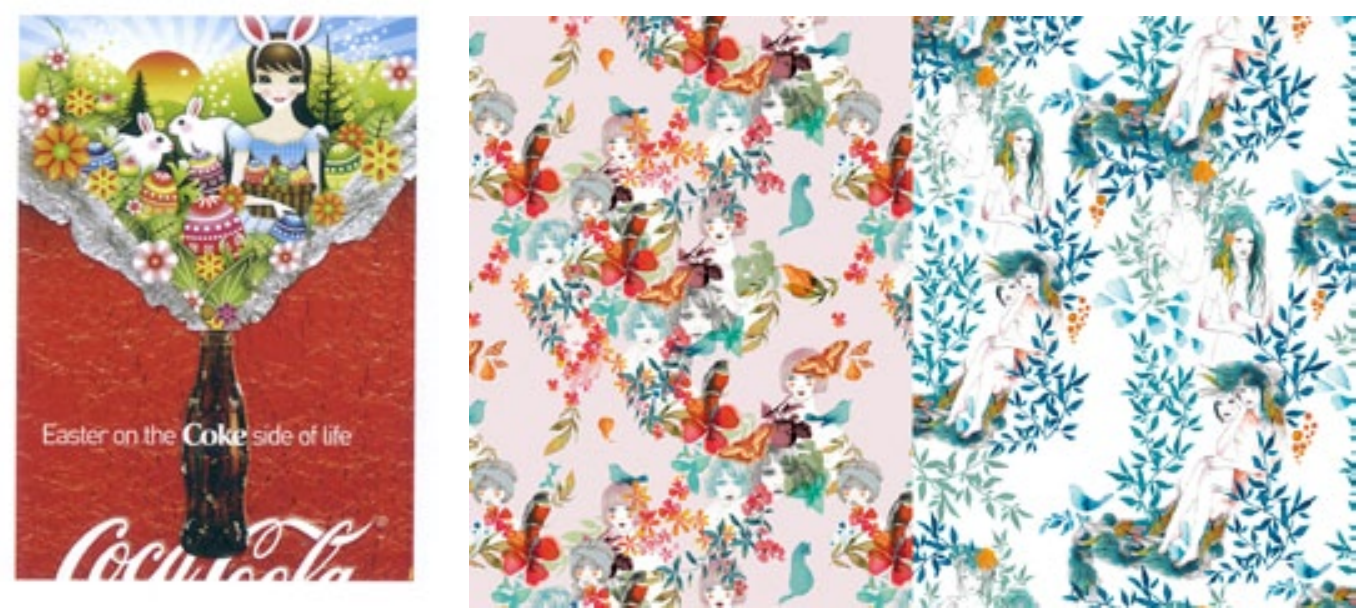

De hecho, la visibilidad alcanzada por los ilustradores gracias a Internet ha impulsado su contratación por parte de firmas de moda y decoración para el hogar, cosmética, tecnología, ocio, etc.; además por supuesto, de sectores de aplicación más tradicionales como prensa y editoriales. Como apunta la ilustradora sueca Stina Persson en Principios de ilustración:

\begin{abstract}
Desde que la ilustración de moda se puso nuevamente "de moda", muchas empresas y publicaciones que no tenían ninguna relación directa con la moda han empezado a contagiarse de su estilo. (...) Quizá este uso extensivo de la ilustración de moda ayuda a aumentar la sensación de que este tipo de ilustración se encuentra en todas partes. (Zeegen, L./Crush, 2006:99).
\end{abstract}

\section{Conclusión.}

\section{Referencias bibliográficas.}

A lo largo de este proyecto de investigación hemos podido corroborar como la situación de la disciplina que nos ocupa ha evolucionado favorecida por las herramientas digitales. Consideramos un hecho evidente que la ilustración ha regresado a escena tras un largo paréntesis- a excepción quizás del sector del libro infantil- motivado por la imposición de la imagen fotográfica durante décadas. Creemos que este estudio muestra como la ilustración se perfila hoy como una opción versátil y novedosa adaptable a diversos ámbitos normalmente vinculados a la cultura popular.

LA SANTA. (2009). Graphic Fashion. Design, Illustration and Trends. Barcelona: Promopress.

Quinn, B. (2009).Textiles. Diseñadores de vanguardia. Barcelona: Blume.

Zeegen, L. (2007). Ilustración digital. Barcelona: Promopress.

Zeegen, L./Crush (2006). Principios de ilustración. Barcelona: Gustavo Gil. 